УДК 338.24

\title{
ОРГАНИЗАЦИЯ УПРАВЛЕНИЯ РЕГУЛЯТОРНЫМ РИСКОМ В КОММЕРЧЕСКОМ БАНКЕ
}

\author{
Р. А. Кириллов \\ кандидат экономических наук, эксперт 1-й категории \\ Департамента допуска на финансовый рынок, \\ Банк России, Москва \\ E-mail: 1331949@mail.ru
}

\section{А. А. Фирсова}

доктор экономических наук, заведующая кафедрой банковского менеджмента, Саратовский национальный исследовательский государственный университет имени Н. Г. Чернышевского E-mail: a.firsova@rambler.ru

\section{А. В. Вавилина}

кандидат экономических наук, доцент кафедры менеджмента, Российский университет дружбы народов (РУДН), Москва E-mail: vavilinaalla@mail.ru

\section{О. Ю. Кириллова}

кандидат экономических наук, профессор кафедры экономики, Институт международных экономических связей, Москва E-mail: cg_123@mail.ru

Введение. Отсутствие в российской корпоративной практике единой концепции по формированию систем внутреннего контроля коммерческого банка и методического обеспечения процессов управления регуляторным риском обусловливает актуальность развития теории и методологии подходов к организации внутреннего контроля и управлению регуляторным риском в коммерческом банке. Теоретический анализ. Регуляторные риски проявляются с возникновением предусмотренной законом или иным нормативным правовым актом прямой или косвенной возможности воздействия ограничительного характера со стороны государственных органов на бизнес-процессы коммерческого банка. Организация управления регуляторным риском коммерческого банка состоит в деятельности должностных лиц и структурных подразделений компаний, направленной на предупреждение и снижение вероятности возникновения регуляторных рисков, создание комфортной правовой среды ведения бизнеса. Эмпирический анализ. Для осуществления внутреннего контроля и содействия органам управления банка в обеспечении его эффективного функционирования, роста и развития создается служба внутреннего контроля как элемент внутреннего контроля коммерческого банка. Результаты. Преобладающее большинство руководителей структурных подразделений признают полезность и нужность внедрения мер по организации контроля регуляторных рисков, причем особую важность имеет не столько получение значения уровня регуляторного риска, выраженного конкретным числом, сколько формирование нормативно-правовой платформы деятельности подразделения.

Ключевые слова: коммерческие банки, управление риском, система внутреннего контроля, регуляторный риск, служба внутреннего контроля.

DOI: 10.18500/1994-2540-2016-16-4-440-444

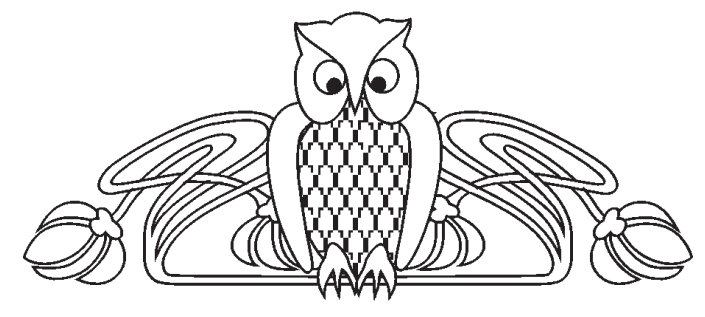

\section{Введение}

Резкий рост количества нормативных правовых актов в банковской деятельности в последние десятилетие, усложнение правоприменительной практики, появление новых уголовных и административных составов правонарушений, отсутствие единого порядка взаимодействия подразделений банков с госорганами, сложная структура взаимодействия компаний с государственными органами вызывают необходимость организации учета воздействия регуляторных рисков на деятельность коммерческих банков.

В основном документе - Положении ЦБ РФ № 242-П «Об организации внутреннего контроля в кредитных организациях и банковских группах», Указанием Банка России № 3241-У от 24.04.2014 не установлено четких ориентиров для формирования систем внутреннего контроля, а инспекторы Банка России, проверяя тот или иной банк, не располагают нормативно закрепленными критериями оценки эффективности внутреннего контроля [1].

Вследствие отсутствия в российской корпоративной практике единой концепции по формированию систем внутреннего контроля коммерческого банка и методического обеспечения процессов управления регуляторным риском актуальны дальнейшее развитие теории и методологии обозначенных проблем и разработка новых практических подходов к организации внутреннего контроля и управлению регуляторным риском в коммерческом банке.

\section{Теоретический анализ}

Управление регуляторными рисками является одной из главных составляющих эффективного управления кредитной организацией.

Регуляторный риск - это риск несоблюдения внешних или внутренних норм, касающихся любых аспектов деятельности, и, как следствие, риск возникновения негативных финансовых или иных последствий для коммерческого банка.

Регуляторные риски проявляются с возникновением предусмотренной законом или иным нормативным правовым актом прямой или косвенной (вызванной нечеткостью формулировок) 
возможности воздействия ограничительного характера со стороны государственных органов на бизнес-процессы коммерческого банка. К ним относят риски возникновения у банка убытков из-за несоблюдения законодательства Российской Федерации, положений внутренних документов банка, стандартов саморегулируемых организаций (если такие стандарты или правила являются обязательными для банка), а также риски, наступающие в результате применения санкций и иных мер воздействия со стороны надзорных органов. Регуляторные риски обнаруживают себя на ранней стадии, до момента появления проблемы [2].

Организация управления регуляторным риском коммерческого банка состоит в деятельности должностных лиц и структурных подразделений компаний, направленной на предупреждение и снижение вероятности возникновения регуляторных рисков, создание комфортной правовой среды ведения бизнеса

Профессиональный подход к выстраиванию процесса управления регуляторным риском требует соотнесения его с современными требованиями, предъявляемыми к системам внутреннего контроля банков.

Кодекс корпоративного управления, рекомендованный Письмом Банка России от 10.04.2014 № 06-52/2463 «О Кодексе корпоративного управления», в части, посвященной принципам, обязывает банки к внедрению «эффективно функционирующей системы управления рисками и внутреннего контроля, направленной на обеспечение разумной уверенности в достижении поставленных перед обществом целей». Эта система «должна обеспечивать объективное, справедливое и ясное представление о текущем состоянии и перспективах общества, целостность и прозрачность отчетности общества, разумность и приемлемость принимаемых обществом рисков». При этом совету директоров рекомендуется принимать «необходимые достаточные меры для того, чтобы убедится, что действующая в обществе система управления рисками и внутреннего контроля соответствует определенным советом директоров принципам и подходам к ее организации и эффективно функционирует» [3].

Основными задачами управления регуляторным риском в коммерческих банках являются следующие:

- получение достоверной информации о состоянии регуляторного риска;

- определение приемлемого уровня регуляторного риска для банка;

- разработка процедур внутреннего контроля, направленных на предотвращение/минимизацию последствий реализации регуляторного риска для банка;
- постоянный мониторинг регуляторного риска;

- совершенствование подходов к управлению регуляторным риском.

\section{Эмпирический анализ}

Для осуществления внутреннего контроля и содействия органам управления банка в обеспечении его эффективного функционирования, роста и развития создается служба внутреннего контроля как элемент внутреннего контроля коммерческого банка.

Стандартный подход в организации процесса внутреннего контроля в системе корпоративного управления изложен в Положении ЦБ РФ № 242-П [1]. Согласно его предписанию служба внутреннего контроля должна иметь график проведения плановых проверок, составленный с учетом принятой в компании периодичности проверок и соответствующий деятельности структурных подразделений.

Особое внимание при разработке плана рекомендуется уделять:

- зонам повышенного риска, для чего целесообразно провести оценку и составить рейтинги по видам каждого риска в отдельности;

- подразделениям и функциям банка, где в ходе предыдущих проверок были обнаружены и зафиксированы значительные отклонения от плановых показателей, выявлены нарушения норм и регламентов деятельности, обнаружены факты высокой текучести кадров, конфликтов и т.П. В случае необходимости в план могут вноситься изменения при условии их согласования с руководством банка.

Для каждой проверки госрегулятор обязывает разработать программу, в которой как минимум заявлены цели проверки, контролируемые риски, требования по обеспечению полноты и эффективности контроля в бизнес-процессах проверяемого структурного подразделения. Программа проверки утверждается руководителем службы внутреннего контроля. Необходимо отметить, что описанные обязательные требования установлены рамочно, не детализированы, что несет в себе риск некачественного выполнения контрольных обязанностей, вмененных сотрудникам службы внутреннего контроля.

Выстраивая систему внутреннего контроля в корпорации, ее разработчики должны отчетливо понимать, что контроль - не самоцель, а лишь одно из средств эффективного достижения поставленных целей. Приоритет же всегда будет отдаваться развитию бизнеса и получению прибыли. Слишком много контроля для бизнеса может быть так же губительно, как и его недостаток. 
Процесс управления регуляторным риском банка составляют четыре основные функции:

- выявление регуляторного риска;

- оценка регуляторного риска;

- мониторинг регуляторного риска;

- контроль регуляторного риска.

Стандартный алгоритм контроля выглядит следующим образом:

1) формирование стандартов и критериев т.е. базы для последующего сравнения, принятой в банке, либо заданной извне, либо основанной на рациональности понимания ситуации в сфере контроля;

2) определение фактического состояния или действия управляемого подразделения системы управления (объекта контроля);

3) сравнение фактических данных с требуемыми;

4) оценка отклонений, превышающих предельно допустимый уровень, на предмет степени их влияния на аспекты функционирования корпорации;

5) выявление причин данных отклонений;

6) принятие необходимых корректирующих действий.

Одним из неотъемлемых элементов функций оценки и мониторинга является определение уровня регуляторного риска структурных подразделений и компании в целом. С этой целью разработана и апробирована методика оценки уровня приемлемости регуляторного риска в отдельном структурном подразделении, позволяющая также рассчитать его значение и по компании в целом [4].

Согласно концепции трех линий защиты можно определить место и задачи функции управления регуляторным риском в коммерческих банках следующим образом.

Первый уровень контроля - это уровень структурного подразделения. Структурные подразделения выступают владельцами рисков и должны отчетливо понимать их состав, последствия и причины возникновения. Именно поэтому процесс управления регуляторным риском на уровне структурного подразделения должен начинаться с осознания каждым сотрудником того, какие регуляторные риски сопровождают его деятельность, а также с понимания ответственности за конкретный вид риска.

Существуют и другие положительные стороны развития системы внутреннего контроля на «нижнем» уровне. Например, соответствие международным стандартам и достоверность финансовой отчетности ведут к повышению доверия со стороны инвесторов как одних из ключевых участников корпоративных отношений. Популяризация этических норм является признаком заботы компании о своих сотрудниках, что может привести к повышению лояльности к компании и руководству со стороны персонала.

Второй уровень контроля предполагает наличие структурного подразделения, осуществляющего профессиональное управление регуляторным риском. Данное подразделение разрабатывает и поддерживает процесс контроля регуляторного риска, определяет технологию и этические стандарты его осуществления.

Третий уровень контроля связан с работой внутренних аудиторов и совета директоров компании. В совете директоров функция контроля регуляторных рисков взаимосвязана, прежде всего, с работой комитетов по аудиту, управлению рисками и по стратегическому развитию. Именно совет директоров оценивает и в конечном итоге утверждает уровень рисков банка («риск-аппетит») (рисунок).

\section{Результаты}

По данным исследования Pricewaterhouse Coopers, на вопрос о вовлеченности структурных подразделений в процесс управления рисками лишь 25\% участников ответили, что структурные подразделения в их компании принимают активное участие в этом процессе, т.е. действительно своевременно выявляют риски, подготавливают необходимую отчетность и внедряют мероприятия по управлению ими, 37\% опрошенных респондентов отметили, что наибольшую выгоду системе управления рисками принесет мера по организации взаимодействия между департаментом по управлению рисками и бизнес-подразделениями, а $17 \%$ - усиление поддержки со стороны руководства [5].

Эти данные свидетельствуют о проблемах в организации взаимодействия между первым и вторым уровнями контроля.

Встраивание элементов методики определения уровня регуляторного риска сопровождается сопротивлением персонала. Это неизбежно по ряду объективных причин. Во-первых, из-за отсутствия/недостаточности информации у сотрудников, для чего это нужно. Отчасти это связано с восприятием информации: части сотрудников, как правило, недостаточно письменной инструкции. Понятие «регуляторный риск» находится в отрыве от оперативной деятельности. Для того чтобы каждый сотрудник понял его значение для себя, необходима определенная разъяснительная работа. Без понимания ответственности и собственного участия в возникновении данного вида риска отношение к определению его уровня будет формальным. Поэтому такая работа должна вестись совместно с сотрудниками HR-службы, 


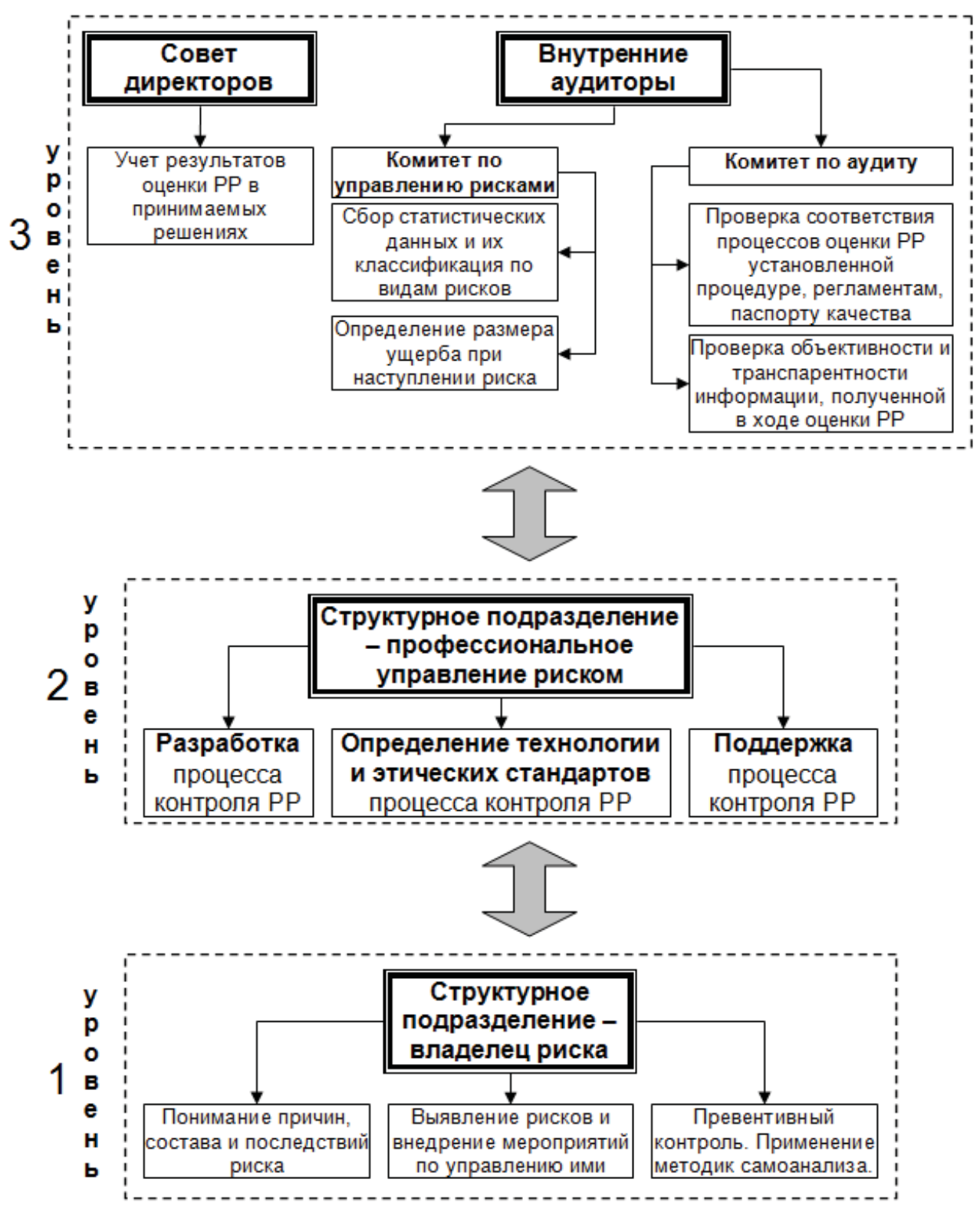

Уровни организации контроля регуляторных рисков коммерческого банка

которые обязаны четко определить место итогов оценивания в системе мотивации сотрудников (как влияет данная оценка на размер денежного вознаграждения, карьерный рост и прочие факторы взаимодействия компании и сотрудника).

Также очевидна потребность в обратной связи в виде обсуждения смысла вопросов анкеты, значения интервалов шкалы оценки, содержания отдельных понятий. Иными словами, необходимо применение приемов классических методов социального опроса, технология которых заключается в выравнивании мнений репрезентативного состава участников в плане понимания и отношения участников опроса к запрашиваемой информации.
Вместе с тем преобладающее большинство руководителей структурных подразделений признают полезность и нужность внедрения мер по организации контроля регуляторных рисков, причем особую важность имеет не столько получение значения уровня регуляторного риска, выраженного конкретным числом, сколько формирование нормативно-правовой платформы деятельности подразделения.

\section{Список литературы}

1. О внесении изменений в Положение Банка России от 16 декабря 2003 года № 242-П «Об организации внутреннего контроля в кредитных организациях и банковских группах» : указание Банка России от 
24.04.2014 № 3241-У. URL: http://www.cbr.ru/publ/ vestnik/vestnik/ves140709063.pdf (дата обращения: 07.11.2014) .

2. Ибрагимов Р. С. Об управлении регуляторными рисками. URL: http://www.kluwerevents.ru/file/080930/ Ibragimov.pdf (дата обращения: 05.09.2013).

3. О Кодексе корпоративного управления : письмо Банка России от 10.04.2014 № 06-52/2463. Доступ из справ.-правовой системы «КонсультантПлюс».

4. Кириллов Р. А. Оценка уровня приемлемости регуляторного риска в структурном подразделении // Управление в кредитной организации. 2015. № 3 (79). C. $18-30$.

5. Нисенбойм Л. Каждый думает о рисках // Консультант. 2011. № 13. URL: http://www.cfin.ru/finanalysis/risk/ each.shtml (дата обращения: 07.10.2015).

\section{Образец для цитирования:}

Кириллов Р. А., Фирсова А. А., Вавилина А. В., Кириллова О. Ю. Организация управления регуляторным риском в коммерческом банке // Изв. Сарат. ун-та. Нов. сер. Сер. Экономика. Управление. Право. 2016. Т. 16, вып. 4. C. 440-444. DOI: 10.18500/1994-2540-2016-16-4-440-444.

\section{Organization of Regulatory Risk Management in Commercial Bank}

\section{R. A. Kirillov}

The Central Bank of the Russian Federation, 12, Neglinnaya str., Moscow, 107016, Russia

E-mail: 1331949@mail.ru

\section{A. A. Firsova}

Saratov State University,

83, Astrakhanskaya str., Saratov, 410012, Russia

E-mail: a.firsova@rambler.ru

\section{A. V. Vavilina}

Peoples' Friendship University of Russia,

6, Miklukho-Maklaya str., Moscow, 117198, Russia

E-mail: vavilinaalla@mail.ru

\section{O. Yu. Kirillova}

The Institute of International Economic Relations, 35, Mosfilmovskaya str., Moscow, 119330, Russia E-mail: cg_123@mail.ru

Introduction. The absence of Russian corporate practice on the formation of a unified concept of internal control of commercial bank and methodological support of regulatory risk management process determines the relevance of the theory and methodology of approaches to the organization of internal control and management of regulatory risk in a business bank. Theoretical analysis. Regulatory risks are manifested with the emergence of the statutory or other regulatory legal act of direct or indirect exposure to the possibility of limiting the part of state bodies on the business processes of a commercial bank. Organization of management of the commercial bank regulatory risk consists in the activities of officials and divisions of companies, aimed at preventing and reducing the likelihood of regulatory risks, creating a comfortable legal environment for doing business. Empirical analysis. For the implementation of internal controls and facilitating the bank's management bodies in ensuring its effective functioning, growth and development created the Internal Control as an element of internal control of commercial bank. Results. The vast majority of heads of departments recognize the usefulness and necessity of the implementation of measures to control the organization of regulatory risk, and is of particular importance not only to obtain regulatory risk level values expressed by a specific number, as the formation of the regulatory activity of the platform unit.

Key words: commercial banks, risk management, internal controls, regulatory risk, internal control service.

\section{References}

1. O vnesenii izmeneniy v Polozhenie Banka Rossii ot 16 dekabria 2003 goda № 242-P «Ob organizatsii vnutrennego kontrolia $v$ kreditnykh organizatsiyakh i bankovskikh gruppakh»: ukazanie Banka Rossii ot 24.04.2014 № 3241-U (On Amendments to the Bank of Russia Regulation of 16 December 2003 № 242-P «On organization of internal control in credit institutions and banking groups». Directive of the Bank of Russia of 24.04.2014 № 3241-U). Available at: http://www.cbr. $\mathrm{ru} / \mathrm{publ} / \mathrm{vestnik} /$ vestnik/ves 140709063.pdf (accessed 7 November 2014).

2. Ibragimov R. S. Ob upravlenii reguliatornymi riskami (On the management of regulatory risk). Available at: http://www.kluwerevents.ru/file/080930/Ibragimov.pdf (accessed 5 September 2013).

3. O Kodekse korporativnogo upravleniia: pis'mo Banka Rossii ot 10.042014 № 06-52/2463 (About the Code of Corporate Governance. Bank of Russia Letter of 10.04.2014 № 06-52/2463). ATP «Consultant» [electronic resource].

4. Kirillov R. A. Otsenka urovnia priemlemosti reguliatornogo riska $\mathrm{v}$ strukturnom podrazdelenii [Evaluation of the acceptability of the regulatory risk in the structural department]. Upravlenie v kreditnoi organizatsii [Management in the credit institution], 2015, no. 3 (79), pp. 18-30.

5. Nisenboim L. Kazhdyi dumaet o riskakh (Everybody thinks about the risks). Konsul 'tant (Consultant), 2011, no.13. Available at: http://www.cfin.ru/finanalysis/risk/ each.shtml (accessed 7 October 2015).

\section{Please cite this article in press as:}

Kirillov R. A., Firsova A. A., Vavilina A. V., Kirillova O. Yu. Organization of Regulatory Risk Management in Commercial Bank. Izv. Saratov Univ. (N.S.), Ser. Economics. Management. Law, 2016, vol. 16, iss. 4, pp. $440-444$ (in Russian). DOI: 10.18500/1994-2540-2016-16-4-440-444. 